\title{
Evidence for negative association of the chemokine receptor CCR5 d32 polymorphism with rheumatoid arthritis
}

\author{
V Pokorny, F McQueen, S Yeoman, M Merriman, A Merriman, A Harrison, \\ J Highton, L McLean
}

Background: Ligands of chemokine receptor CCR5, including MIP- $1 \alpha$, MIP-1 $\beta$, and RANTES, have been implicated in rheumatoid arthritis.

Objective: To test whether CCR5 d32 polymorphism has a negative association with rheumatoid arthritis in a New Zealand cohort.

Methods: 516 white patients with rheumatoid arthritis and 985 healthy controls were investigated by PCR amplification of the region flanking the known CCR5 d32 deletion, and the frequencies of CCR5 d32 compared. An early rheumatoid arthritis (ERA) cohort of 92 patients was followed prospectively for two years; disease severity and outcome were correlated with CCR5 $d 32$ status.

Results: 12 control subjects (1.2\%) were homozygous for d32; no d32 homozygous rheumatoid patients were detected ( $p=0.012) ; 56$ patients $(10.9 \%)$ were heterozygous for the d32 polymorphism (d32/wt), compared with 169 controls (17.2\%) $(p=0.0011)$. The CCR5 $d 32$ allele frequency was lower in the rheumatoid patients than in the controls (frequencies of 0.054 and 0.098 , respectively; $p=3.7 \times$ $\left.10^{-5}\right)$. The frequency of CCR5 $\mathrm{d} 32 \mathrm{did}$ not differ significantly according to disease severity or outcome in the prospective ERA cohort, nor with HLA-DRB1 status.

Conclusions: This study provides further evidence for a protective effect of the CCR5 d32 variant on rheumatoid arthritis, consistent with a role for CCR5 and its ligands in disease pathogenesis.

$\mathrm{R}$ heumatoid arthritis is characterised by synovial infiltration with $\mathrm{T}$ lymphocytes and macrophages, leading to pannus formation associated with damage to the underlying cartilage and bone in many patients. To participate in synovitis, these inflammatory cells need to enter the synovium. Among the stimuli for cell movement is the chemotactic gradient provided by chemokines, a large group of low molecular weight cytokines that act on different subgroups of leucocytes. The CCR5 chemokine ligands macrophage inflammatory protein-1 $\alpha$ (MIPl $\alpha$; CCL3), MIPI $\beta$ (CCL4), and RANTES (regulated upon activation, normal $\mathrm{T}$ cell expressed and secreted; CCL5) are expressed in rheumatoid synovial tissue, and CCR5 is present on macrophages and on most Thl lymphocytes including $\mathrm{T}$ lymphocytes in rheumatoid synovial fluid and membrane. ${ }^{1-4}$

The factors controlling the aetiology of rheumatoid arthritis are complex. Genes contribute around 50\% of the susceptibility to the disease, with probable interactions between genes at different loci, each contributing a small amount of overall risk for the disease; unidentified environmental factors control the remaining portion of the aetiology. ${ }^{5}$ The major known genetic contribution to rheumatoid arthritis is from HLA-DRBl, but overall the HLA region accounts for a minority of the genetic contribution. ${ }^{6} \mathrm{~A}$ 32 base pair (bp) deletion in the CCR5 gene (CCCKR5, CMKBR5, CKR5; OMIM 601373; CCR5 d32) results in a frame shift and premature termination in the region encoding the second extracellular loop of the CCR5 receptor, producing a non-functional receptor associated with resistance to activation by specific chemokines, and also with reduced in vitro susceptibility to HIV-l infection. ${ }^{7}$ Previous studies have suggested an influence of CCR5 $\mathrm{d} 32$ on rheumatoid arthritis. $^{8-12}$ We examined the frequencies of the CCR5 d 32 allele in a large cohort of rheumatoid patients and healthy controls and the effect on the severity and progression of the disease in a prospective early rheumatoid arthritis cohort, looking for possible interactions between HLA-DRBI and CCR 5 d 32 .

\section{METHODS}

\section{Study subjects}

We recruited 516 unrelated white New Zealanders with rheumatoid arthritis (368 female, 148 male) who fulfilled the revised criteria of the American Rheumatism Association (later the American College of Rheumatology (ACR)) for the diagnosis of rheumatoid arthritis. They were patients attending rheumatology outpatient clinics at tertiary referral centres within New Zealand. Ninety two rheumatoid patients were part of a prospective early rheumatoid arthritis (ERA) study and have had regular detailed follow up as reported previously. ${ }^{13}$ Healthy control subjects comprised 985 white donors (526 female, 459 male) attending the Auckland Regional Blood Service. The study had ethics committee approval and all subjects provided written informed consent.

\section{Genotyping and analysis}

Genomic DNA was extracted from anticoagulated whole blood using a sucrose lysis buffer and DNAzol (Invitrogen), and then amplified by polymerase chain reaction (PCR) using oligonucleotide primers spanning the CCR 5 d 32 region (CDNA nucleotides (nt) 794-825 relative to GenBank NM000579): CCR5 Pl 5'-TTT ACC AGA TCT CAA AAA GAA G (sense) and CCR5 P2 5'-GGA GAA GGA CAA TGT TGT AGG (antisense). ${ }^{3}$ Reaction mixtures (15 $\mu \mathrm{l})$ containing DNA (100 ng), oligonucleotide primers $(0.5 \mu \mathrm{M})$, dNTPs $(200 \mathrm{mM})$, buffer consisting of $10 \mathrm{mM}$ Tris- $\mathrm{HCl}(\mathrm{pH} \mathrm{8.4)}, 50 \mathrm{mM} \mathrm{KCl}$, and 1.25 mM $\mathrm{MgCl}_{2}$; and 1 unit of DNA polymerase were heated to $94^{\circ} \mathrm{C}$ for three minutes and then subjected to

Abbreviations: ERA, early rheumatoid arthritis; RANTES, regulated upon activation, normal T cell expressed and secreted; SE, shared epitope 


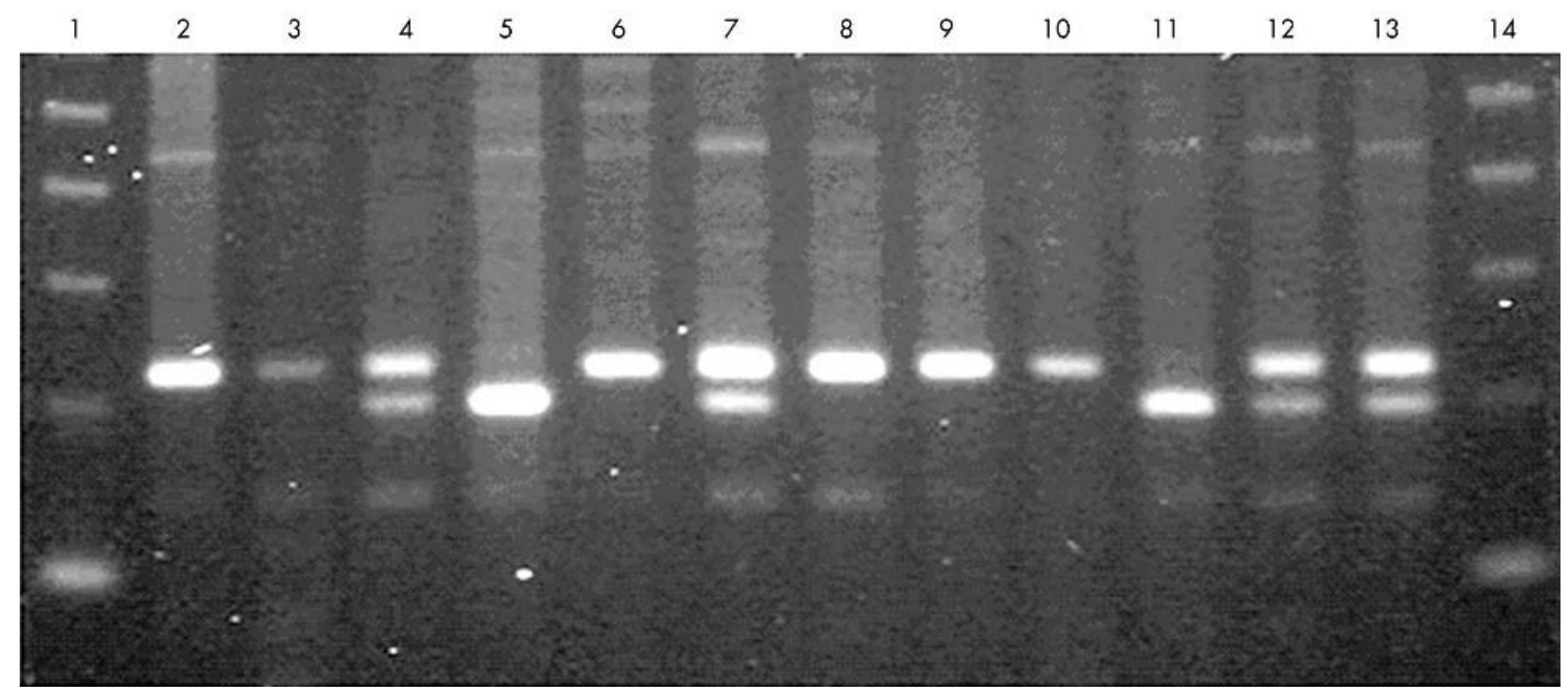

Figure 1 Analysis of CCR5 genotype in rheumatoid arthritis and controls by polymerase chain reaction (PCR). Agarose gel electrophoresis of PCR products. Wild type CCR5 gene PCR amplicon 274 bp, d32 amplicon 242 bp. Lanes 1 and 14, molecular weight markers (123 bp ladder) of 123 bp, 246 bp, 369 bp, etc; lanes 2, 3, 6, 8, 9, and 10, homozygous CCR5 wt/wt; lanes 4, 7, 12, and 13, heterozygous CCR5 d32/wt; lanes 5 and 11, homozygous CCR5 $\mathrm{d} 32 / \mathrm{d} 32$ deletion allele.

35 amplification cycles of $94^{\circ} \mathrm{C}$ for 30 seconds, $62^{\circ} \mathrm{C}$ for one minute, and $72^{\circ} \mathrm{C}$ for one minute, followed by a final elongation cycle of $72^{\circ} \mathrm{C}$ for five minutes. The PCR products were visualised on ultraviolet transilluminated, ethidium bromide stained $2 \%$ agarose gels after electrophoresis, yielding PCR products of 274 and $242 \mathrm{bp}$ for the CCR5 wt and $\mathrm{d} 32$ alleles respectively (fig 1). Typing for $H L A-D R B 1$ was done with a sequence specific primer $\mathrm{PCR}^{14}$ or a single stranded oligoprobe PCR (DRBI LiPA, Innogenetics). High resolution HLA-DRBl typing was done on ERA subjects by DNA sequencing, and the HLA-DR shared epitope (SE) status was considered positive in the presence of HLA-DRBI*0101, 0401, *0404, *0405, *0408, *1001, or *1402; no other DRB 1 alleles with the codon 70-74 QKRAA, QRRAA or RRRAA sequence were detected.

Subjects were considered to be homozygous if the low resolution typing indicated only one HLA-DRBl type and manual review of the sequencing electropherograms showed a single peak for every nucleotide.

\section{Statistics}

The two tailed Fisher exact test was carried out to determine the statistical significance of differences in genotype and allele distributions, and the Mann-Whitney U test was used to compare continuous variables. Prism version 3.00 and InStat version 3.00 (GraphPad Software) were used for statistical analysis.

\section{RESULTS}

The genotype and allele frequencies of the $32 \mathrm{bp}$ deletion are summarised in table 1 . Eleven per cent of patients were heterozygous for the $\mathrm{d} 32$ polymorphism $(\mathrm{d} 32 / \mathrm{wt})$, compared with $17 \%$ of controls $(p=0.0011)$. In the rheumatoid patients the CCR5 d32 allele frequency (0.054) was significantly lower than in the healthy controls $(0.098$; odds ratio $=0.51 \quad(95 \%$ confidence interval (CI), 0.37 to 0.69 ); $\mathrm{p}=3.7 \times 10^{-5}$ ). Although $12 \mathrm{~d} 32 / \mathrm{d} 32$ deletion homozygotes were present in the 985 controls $(1.2 \%)$, none was detected among the 516 rheumatoid patients $(p=0.012)$. In the ERA cohort, after correcting for multiple testing, CCR5 d32 status was not associated with a significant difference in disease severity as assessed by baseline or follow up tender or swollen joint counts, rheumatoid factor status, erythrocyte sedimentation rate, $\mathrm{C}$ reactive protein, disease modifying antirheumatic drug usage, health assessment questionnaire/disease index, radiographic erosion status, or (in a subcohort described

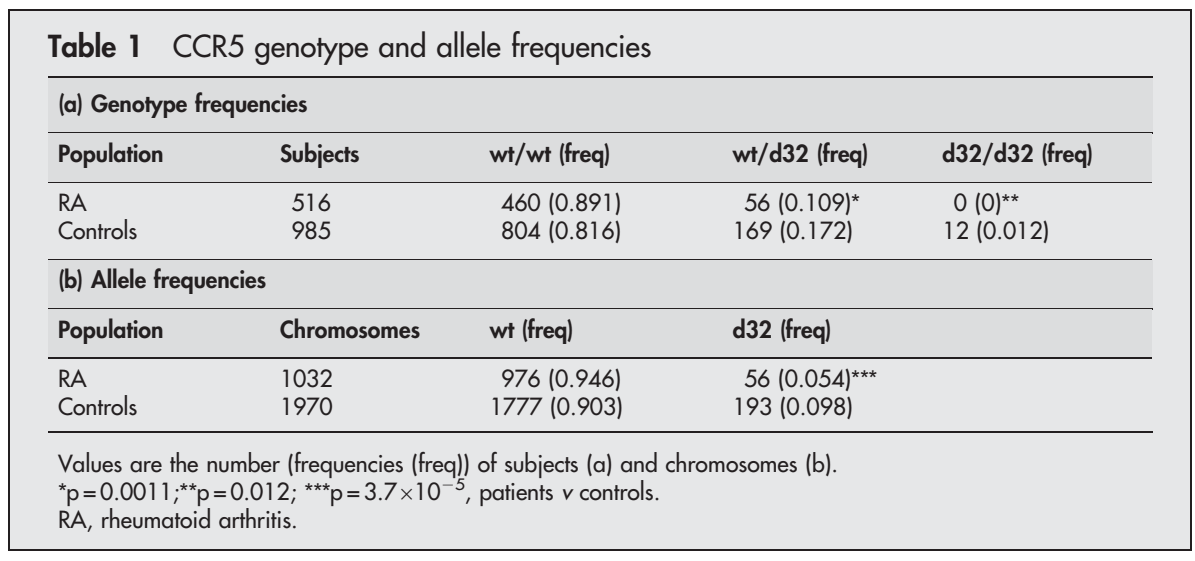


previously $\left.{ }^{13}\right)$ by dominant wrist magnetic resonance image scoring (data not shown). In the ERA group, 13 (14.1\%) were heterozygous (d32/wt). None was d32/d32 homozygous.

The CCR5 d32 genotypes complied with the HardyWeinberg equilibrium, and the frequencies in the control subjects were compatible with those in other published studies of European white subjects. ${ }^{8-12}$

Low resolution HLA-DRBI typing had been done for 475 of the rheumatoid patients and 912 controls. As expected, carriage of a DRBI*04 allele was significantly higher in rheumatoid $(276 / 475,53.4 \%)$ than in control subjects (199/ $912,21.2 \%)(\mathrm{p}<0.0001)$. Among the 92 ERA patients, 48 $(52.2 \%)$ were DR4 positive and $67(72.8 \%)$ were SE positive. The HLA-DRBl*04 and SE positivity frequencies did not differ significantly according to CCR5 $\$ 32$ status (data not shown).

\section{DISCUSSION}

We investigated the CCR5 gene 32 bp deletion polymorphism in a large cohort of rheumatoid patients and controls, comprising over 1500 individuals. In this rheumatoid arthritis cohort the CCR5 $\mathrm{d} 32$ allele frequency in patients $(5.4 \%)$ was significantly reduced in comparison with that in the healthy individuals $(9.8 \%)$, and there was a striking absence of rheumatoid patients who were homozygous for the mutated receptor gene. We did not show an effect on disease severity, nor any interaction of the CCR5 d32 polymorphism with HLA-DRBI*04 or SE status; however, our cohort size may have been too small to show these effects.

This study is the first to demonstrate a significant negative association of the CCR5 $\mathrm{d} 32$ polymorphism with rheumatoid arthritis $(p<0.0001)$. We replicated the finding of GomezReino et al, ${ }^{10}$ who also reported a negative association of the CCR5 d32/d32 homozygous genotype with rheumatoid arthritis (no d32/d32 individuals among 673 Spanish patients with rheumatoid arthritis). Three other studies examining the association of CCR $\$ 32$ with rheumatoid arthritis have reported no nominally significant differences $(p<0.05)$ in frequency between rheumatoid cases and healthy controls (d32/wt genotype frequencies $19.2 \%$ and $13.7 \% ; 24.5 \%$ and $18.4 \%$; and $16.8 \%$ and $11.3 \%$, respectively). ${ }^{8}{ }^{11}$ This apparent inconsistency may reflect one or a combination of several factors: heterogeneity in the detection and referral patterns of rheumatoid arthritis according to disease severity; differences in rheumatoid arthritis aetiology between the ethnic and geographic origins of subjects; or inadequate power. Some studies of white subjects of British, Danish, and Spanish origin have provided no evidence for an association of CCR5 d32 with rheumatoid arthritis per se, ${ }^{8911}$ whereas others, such as the present study, in white New Zealanders, and that of Gomez-Reino et $a l^{10}$ in white Spanish subjects, do provide evidence for an association. Thus there is no indication that the ethnic origin of the subjects is a major factor in the discrepancy in CCR5 d32 association data between studies.

We speculate that inadequate power of studies is more likely to account for the lack of replication. The wild type allele at CCR5 $d 32$ confers an odds ratio of 1.89 (95\% CI, 1.39 to 2.57) for developing rheumatoid arthritis in our cohort. Using a conservative odds ratio estimate of 1.39 (the lower bound of the confidence interval), the largest of the three studies to find no evidence for an association (Cooke et al, ${ }^{8}$ 278 patients) had only $16 \%$ power $(\alpha=0.01)$. An equivalent post priori calculation reveals that our cohort had $44 \%$ and that of Gomez-Reino et $a l^{10} 34 \%$ power $(\alpha=0.01$ ). (Power calculations were made as previously described. ${ }^{15}$ ) Although these power calculations are stringent (using a conservative odds ratio estimate and $\alpha=0.01$ ), they do indicate that, even with over 500 cases, association studies are still underpowered, and a degree of luck is required to detect an effect of CCR $5 \mathrm{~d} 32$. To have $80 \%$ power $(\alpha=0.01)$ will require at least 1400 cases and an equal number of controls. Stratifying such underpowered cohorts in an attempt to reduce phenotype heterogeneity (disease severity, for example) will further reduce power.

Two other studies done on different populations ${ }^{89}$ each identified two rheumatoid patients with a homozygous CCR5 d32/d32 genotype, suggesting that CCR5 deficiency does not completely prevent rheumatoid arthritis. Furthermore, in the study of John and colleagues, ${ }^{12}$ four patients with inflammatory polyarthritis were homozygous for $\mathrm{d} 32 / \mathrm{d} 32$. However, only two of these patients met ACR criteria for rheumatoid arthritis and both of these subjects remained rheumatoid factor negative and non-erosive five years after onset. Overall, the findings are consistent with CCR5 "deficiency" conferring a degree of protection against this disease. Indeed, CCR5 d 32 has been associated with protection against various other immunological disorders including type 1 diabetes, asthma, multiple sclerosis, glomerulonephritis, allograft rejection, and HIV progression.

Individuals homozygous for the 32 bp deletion allele lack the functional membrane receptor, while heterozygous d 32 carriers have reduced expression. The reduced level of functional chemokine receptors on the cell surface could impair the influx and activation of inflammatory cells. The involvement of inflammatory pathways using CCR5 in the pathogenesis of rheumatoid arthritis suggests the possible utility of pharmacological blockade of CCR5 or its ligands.

\section{ACKNOWLEDGEMENTS}

This work was funded by the Arthritis Foundation of New Zealand, the Auckland Medical Research Foundation, the Health Research Council of New Zealand, the New Zealand Lottery Grants Board, and the Dean's Bequest Fund of the University of Otago.

\section{Authors' affiliations}

V Pokorny, F McQueen, S Yeoman, L McLean, Department of Molecular Medicine and Pathology, University of Auckland, and Department of Rheumatology, Auckland Hospital, Auckland, New Zealand

M Merriman, T Merriman, Department of Biochemistry, University of Otago, Dunedin, New Zealand

A Harrison, Wellington Regional Rheumatology Unit, Hutt Hospital, Wellington, New Zealand

J Highton, Department of Medicine, University of Otago

Conflict of interest: $L M$ is a former employee of AstraZeneca and current employee of Merck and Co.; the work described in this paper was conducted before taking up these appointments.

Correspondence to: Dr Lachy McLean, Clinical Immunology and Analgesia, Merck and Co, RY34B-278, PO Box 2000, Rahway, NJ 07065, USA; iain_mclean@merck.com

Accepted 6 July 2004

Published Online First 26 August 2004

\section{REFERENCES}

1 Wang CR, Liu MF. Regulation of CCR5 expression and MIP-1 la production in $\mathrm{CD} 4+\mathrm{T}$ cells from patients with rheumatoid arthritis. Clin Exp Immunol 2003;132:371-8.

2 Nissinen R, Leirisalo-Repo M, Tiittanen M, Julkunen $H$, Hirvonen $H$, Palosuo T, et al. CCR3, CCR5, interleukin 4, and interferon-gamma expression on synovial and peripheral T cells and monocytes in patients with rheumatoid arthritis. J Rheumatol 2003;30:1928-34.

3 Mack M, Bruhl H, Gruber R, Jaeger C, Cihak J, Eiter V, et al. Predominance of mononuclear cells expressing the chemokine receptor CCR5 in synovial effusions of patients with different forms of arthritis. Arthritis Rheum 1999;42:981-8.

4 Haringman JJ, Ludikhuize J, Tak PP. Chemokines in joint disease; the key to inflammation? Ann Rheum Dis 2004, Apr 13 [Epub ahead of print].

5 MacGregor AJ, Snieder H, Rigby AS, Koskenvuo M, Kaprio J, Aho K, et al. Characterizing the quantitative genetic contribution to rheumatoid arthritis using data from twins. Arthritis Rheum 2000;43:30-7. 
6 Rigby AS, Silman AJ, Voelm L, Gregory JC, Ollier WE, Khan MA, et al. Investigating the HLA component in rheumatoid arthritis: an additive (dominant) mode of inheritance is rejected, a recessive mode is preferred. Genet Epidemiol 1991;8:153-75.

7 Liu R, Paxton WA, Choe S, Ceradini D, Martin SR, Horuk R, et al Homozygous defect in HIV-1 coreceptor accounts for resistance of some multiply-exposed individuals to HIV-1 infection. Cell 1996:86:367-77.

8 Cooke SP, Forrest G, Venables PJ, Hajeer A. The delta32 deletion of CCR5 receptor in rheumatoid arthritis. Arthritis Rheum 1998;41:1135-6.

9 Garred P, Madsen HO, Petersen J, Marquart H, Hansen TM, Freiesleben Sorensen S, et al. CC chemokine receptor 5 polymorphism in rheumatoid arthritis. J Rheumatol 1998;25:1462-5.

10 Gomez-Reino JJ, Pablos JL, Carreira PE, Santiago B, Serrano L, Vicario JL, et al. Association of rheumatoid arthritis with a functional chemokine receptor, CCR5. Arthritis Rheum 1999;42:989-92.
11 Zapico I, Coto E, Rodriguez A, Alvarez C, Torre JC, Alvarez V. CCR5 (chemokine receptor-5) DNA-polymorphism influences the severity of rheumatoid arthritis. Genes Immun 2000;1:288-9.

12 John S, Smith S, Morrison JF, Symmons D, Worthington J, Silman A, et al. Genetic variation in CCR5 does not predict clinical outcome in inflammatory arthritis. Arthritis Rheum 2003:48:3615-16.

13 McQueen FM, Stewart N, Crabbe J, Robinson E, Yeoman S, Tan PL, et al. Magnetic resonance imaging of the wrist in early rheumatoid arthritis reveals progression of erosions despite clinical improvement. Ann Rheum Dis 1999;58:156-63

14 Savelkoul PH, de Bruyn-Geraets DP, van den Berg-Loonen EM. High resolution HLA-DRB1 SSP typing for cadaveric donor transplantation. Tissue Antigens 1995;45:41-8.

15 Johnson GC, Esposito L, Barratt BJ, Smith AN, Heward J, Di Genova G, et al. Haplotype tagging for the identification of common disease genes. Nat Genet $2001 ; 29: 233-7$. 